\title{
Disease Targeted Measures of Health Related Quality of Life (HRQOL) in Patients with Advanced Liver Disease Before and After Liver Transplantation
}

\author{
Teresa Casanovas Taltavull, \\ Maria Carmen Peña-Cala and Eva Rodríguez Bruzos \\ Hospital Universitari de Bellvitge, Institut Català de la Salut, \\ IDIBELL, L'Hospitalet de Llobregat-Barcelona \\ Spain
}

\section{Introduction}

Diseases of the liver are becoming increasingly recognized due to their elevated prevalence and their impact on patients' daily life (Younossi,1998; Armstrong, 2000). Besides, in recent years enormous progress in diagnosis and therapeutics has been made. Currently, liver transplantation is the treatment of choice in selected patients for acute and chronic liver failure (Tomé, 2008; Desai, 2008). Liver transplantation has shown that it improves both survival and perceived changes of quality of life (Tomé, 2008; Duffy, 2010). Survival after liver transplantation is excellent, both in the short and long term. Patient survival rates of approximately $85 \%$ after the first year and $75 \%$ five years after transplantation have been reported in the European Liver Transplant Registry (www.eltr.org).

Quality of life (QOL) is a broad concept which includes all aspects of life such as where and how one lives and the role he/she plays in society (Bergner, 1989). We have to consider that QOL will also be affected by factors such as interactions with the environment, previous experiences, cultural background, life expectancy, family life, social interactions, present circumstances; financial situation, housing and job satisfaction, which are difficult to incorporate in research (Sanders, 2008; Flamme, 2008).

QOL is a complex concept involving patient's perception of his/her ability to perform functions such as work, but also comprises the physical effects of the illness and concomitant psychological conditions, anxiety, depression, stigma and feeling of hopelessness (Gutteling, 2007; Cordoba, 2003). Other related issues are studied such as sexual problems, relationships with his/her family, friends and the healthcare team (Ware, 1992; Carver, 2005; Day, 2009).

The present review focuses on relevant patient-reported outcomes such as self-perceived symptoms (some are related to immunosuppressor drugs), medication adherence and long term HRQOL (Health Related Quality of Life) after liver transplant (Osterberg, 2005). In our opinion, although these are interrelated issues we will consider here the most recent development of HRQOL in advanced liver disease and transplantation (Unal, 2001). 
There is some doubt as to what differentiates HRQOL and QOL. Some concepts that can be encapsulated under the term QOL include social functioning, emotional well-being, role functioning, cognitive functioning, sleep problems, sexual functioning, vitality/energy, pain, life satisfaction, body image and general perceptions of health (Table 1) (Borgaonkar, 2000; van den Plas, 2003). In this chapter we will discuss HRQOL because in clinical practice both concepts HRQOL and QOL are used as equivalents, especially for patients with severe disease.

Due to the multidimensionality of HRQOL, it is not possible to measure every dimension simultaneously, therefore a more limited and focused assessment should be undertaken. In patients with chronic diseases such as advanced liver disease, QOL is based on health parameters, and not on more general factors such as socioeconomic status or housing conditions since these are often considered as not having any relevance to their medical concerns. However, some problems related to finances, corporal image or specific architectural needs are contemplated in relation to some medical conditions as it is done for the study of QOL in oncological patients using specific tools (Roila \& Cortesi, 2001; Gangeri, 2007).

Leisure and recreation, Mobility and self-care, Travel, Walking, Food/drink, Running, Visit friends' homes, Climbing, Vacation, Eating, Nearnes sto toilet facilities, Grooming, Hobbies and sports, Physical endurance, Relationships, Emotional, Intimacy and sexual function, Anger, Body image, Embarrassment, Understanding from others, Anxiety, Coping and support, Irritability, Relations with children and extended family, Happiness, Friendships, Worries or fears, Pain and discomfort, Ability to relax, Chest pain, Frustration, Abdominal pain, Depression/sadness, Abdominal cramps, Satisfaction, Abdominal discomfort, Job-education, Rectal pain, Satisfaction, Back pain, Attendance, Headaches, Concentration, Extra intestinal pain, Task completion, Joint pain, Achievement/promotion, Well being, Financial reward, Energy, Treatment, Fatigue, Efficacy, Sleep, Adverse effects, Self-control

Table 1. Problems, issues and domains of health related quality of ife (HRQOL) studied by questionnaires (Borgaonkar, 2000.)

\section{Methods for studying QOL}

In practice most research has measured HRQOL as a multi-dimensional construct, instruments used to measure it must have at least three core domains: physical, psychological and social (Unal, 2001; Drent, 2009). Broadly speaking QOL measures can be divided into two categories: generic or condition-specific (Patrick, 1989; van den Plas, 2003):

\subsection{Generic questionnaires}

Generic questionnaires are comprehensive and they can apply to different patient populations, allowing comparisons between different diseases. These generic measures have the advantage that the obtained scores can be compared with the scores of other patient populations or with a healthy control group, stratified by age and gender. A recognized disadvantage is that generic instruments are not designed to identify disease specific 
domains which may be important when we want to establish whether clinical changes have occurred and whether or not they are significant (Jay, 2009).

In the last few years one of the major clinical concerns has been to obtain a good level of QOL after therapeutic interventions. It is therefore crucial to study QOL by asking questions which are relevant to the patients (Hays, 2000). The concept of patient reported outcome is related to an in depth study of the meaningful changes perceived by the patients (Gill, 1994).

A patient-reported outcome (PRO) can be defined as "any outcome based on data provided by patients or by patient proxy as opposed to data provided from other sources". PROs that are of importance to liver transplant patients are: symptom experience, medication adherence and HRQOL. The effectiveness of treatment after organ transplantation depends both on the skills of the health care team and on the life-long, active cooperation of the patient. (Bayliss,1999).

The clinical information provided to the patient and caregivers about long-term side effects of drugs, and of the possibility of developing recurrent or "de novo" disease is essential (Nickel, 2002). This means that transplantation will have an impact on the daily life and the well-being of the patient and will remain as a chronic condition (Stewart, 1989). The three most commonly used generic HRQOL instruments are: the Nottingham Health Profile (NHP), the Medical Outcomes Study Short Form-36 (SF-36) and the Sickness Impact Profile (SIP). (Table 2) (Coons, 2000; Hunt, 1980; de Bruin, 1992; Bergner, 1976). All three instruments have sufficient psychometric properties.

The Medical Outcomes Study 36-item Short Form Health Survey (SF-36), consists of 36 items which measure eight scales: physical functioning (PF), (10 items), role limitations due to physical problems (RP), (4 items), bodily pain (BP), (2 items), general health (GH), (5 items), vitality (VT), (4 items), social functioning (SF), (2 items), role limitations due to emotional problems (RE), (3 items), and mental health (MH) (5 items). On the basis of these separate subscales, component summary scores can be calculated to provide a global measure of physical (Physical Component Summary score, PCS) and mental functioning (Mental Component Summary score, MCS), respectively. The scale scores range from 0 to 100, with higher scores indicating a better health status. The PCS and MCS have been standardized on the basis of a normative general population of different countries, with the mean set at 50 (SD 10) (Guyatt,1993) The SF-36 is currently the most used instrument worldwide, and a shorter version is available (SF-12) (Bruns, 2010).

\subsection{Nottingham Health Profile (NHP)}

(1) Part I: 38 questions in 6 subareas, with each question assigned a weighted value; the sum of all weighted values in a given subarea adds up to 100, (Hunt, 1985),

- $\quad$ Energy level (EL): 3,

- $\quad$ Pain $(\mathrm{P}): 8$,

- $\quad$ Emotional reaction (ER): 9,

- $\quad$ Sleep (S): 5,

- Social isolation (SI): 5,

- $\quad$ Physical abilities (PA): 8 
(2) Part II: Seven daily life areas that can cause problems in your present state of health:

- $\quad$ Work (i.e. paid employment);

- Looking after the home (cleaning \& cooking, repairs, odd jobs around the home, etc.);

- Social life (going out, seeing friends, going to the movies, etc.);

- Home life (i.e. relationships with other people in your home);

- Sex life;

- Interests and hobbies (sports, arts and crafts, do-it-yourself, etc.);

- Vacations (summer or winter vacations, weekends away, etc.) (Hunt,1980).

\begin{tabular}{|c|c|c|c|}
\hline $\begin{array}{l}\text { Generic } \\
\text { Tests }\end{array}$ & $\begin{array}{l}\text { Nottingham Health } \\
\text { Profile (NHP) }\end{array}$ & $\begin{array}{l}\text { Medical Outcomes Study } \\
\text { Form (SF-36) }\end{array}$ & $\begin{array}{l}\text { Sickness Impact Profile } \\
\text { (SIP) }\end{array}$ \\
\hline Authors & Hunt et al. 1980, 1985 & $\begin{array}{l}\text { Ware et al. } 1992 \\
\text { Brazier et al. } 1992 \\
\text { (Validation) }\end{array}$ & Bergner et al. 1981 \\
\hline $\begin{array}{l}\text { Number of } \\
\text { items }\end{array}$ & 38 & 36 & 136 \\
\hline $\begin{array}{l}\text { Number of } \\
\text { subscales }\end{array}$ & 6 & 8 & 12 \\
\hline Total score & No & $\begin{array}{l}\text { Yes, -Emotional role** } \\
\text {-Physical role** }\end{array}$ & Yes \\
\hline Reliability & $\begin{array}{l}\text { IC:Cronbach alpha: } 0.70- \\
0.85 \\
\text { TRT.r: } 0.75-0.88\end{array}$ & $\begin{array}{l}\text { IC: Cronbach alpha }>0.84 \\
\text { TRT.r: } 0.60-0.81\end{array}$ & $\begin{array}{l}\text { IC:Cronbach alpha: } 0.94 \\
\text { TRT.r: } 0.87-0.97\end{array}$ \\
\hline Validity* & $\begin{array}{l}\text { CV: Ill vs healthy people } \\
\text { DV: Between groups } \\
\text { with various health } \\
\text { statuses }\end{array}$ & $\begin{array}{l}\text { Conv. V: correlations } \\
\text { between four comparable } \\
\text { dimensions of SF-36 and } \\
\text { NHP were high } \\
\text { DV: Correlations between } \\
\text { non comparable } \\
\text { dimensions of SF-36 and } \\
\text { NHP were low }\end{array}$ & $\begin{array}{l}\text { Conv. V: E.g. Activity of } \\
\text { daily living. } \\
\text { Index:r:0.55-0.61 } \\
\text { DV: E.g. explained } \\
\text { variance of Speech } \\
\text { Pathology Ratings } \\
\text { Clinical and Descriptive } \\
\text { validity }\end{array}$ \\
\hline $\begin{array}{l}\text { Subscales/ } \\
\text { domains }\end{array}$ & $\begin{array}{ll}- & \text { Energy } \\
- & \text { Pain } \\
- & \text { Emotional reactions } \\
- & \text { Sleep, } \\
- & \text { Social isolation } \\
- & \text { Physical mobility } \\
- & \text { Seven activity of } \\
& \text { daily living } \\
& \text { questions }\end{array}$ & $\begin{array}{ll}- & \text { Physical functioning } \\
- & \text { Role limitations due } \\
& \text { to physical problems } \\
- & \text { Bodily pain, } \\
- & \text { General health } \\
- & \text { Vitality, } \\
- & \text { Social function } \\
- & \text { Role limitations due } \\
- & \text { to emotional problem } \\
\text { - } & \text { Mental health }\end{array}$ & \\
\hline
\end{tabular}

IC: Internal consistency; TRT: Test Re-test reliability; CV: Construct validity; Conv. V: Convergent validity; DV: Discriminant validity.

${ }^{*}$ All reported validities have been established

** Mental component score and physical component score

Table 2. Most commonly used generic HRQOL instruments 


\subsection{Disease-specific questionnaires have been developed to be valid only for one specific condition}

A review of QOL instruments used in liver transplantation has been published recently (Jay, 2009). In this article, among others, authors discussed existing QOL instruments with its individual strengths and limitations.

In this chapter we will discuss four specific questionnaires, that have been designed for CLD: (Table 3.) (Gutteling, 2007). In table 3 we present the two more frequently used questionnaires.

\begin{tabular}{|c|c|c|}
\hline $\begin{array}{l}\text { Specific HRQOL } \\
\text { instruments }\end{array}$ & $\begin{array}{l}\text { Chronic Liver Disease } \\
\text { Questionnaire (CLDQ) }\end{array}$ & $\begin{array}{l}\text { Liver Disease Quality of Life } \\
\text { Questionnaire (LDQOL)** }\end{array}$ \\
\hline Authors & Younossi et al.1999 & Gralnek et al.2000 \\
\hline Number of items & 29 & 101 \\
\hline Number of subscales & 6 & 20 \\
\hline Total score & Yes & No \\
\hline Reliability & TRT: IC: 0.59 & $\begin{array}{l}\text { IC: } \\
\text { Cronbach alpha> } 0.70 \\
1 \text { subscale alpha: } 0.62\end{array}$ \\
\hline Validity* & $\begin{array}{l}\text { CV: Worse CLDQ scores } \\
\text { with increased disease } \\
\text { severity }\end{array}$ & $\begin{array}{l}\text { CV: Worse LDQOL scores with } \\
\text { increased disease severity for all } \\
\text { subscales }\end{array}$ \\
\hline Subscales & $\begin{array}{ll}- & \text { Fatigue } \\
- & \text { Activity } \\
- & \text { Emotional function } \\
- & \text { Abdominal } \\
& \text { symptoms } \\
- & \text { Systemic symptoms } \\
- & \text { Worry }\end{array}$ & $\begin{array}{l}8 \text { subscales of the SF-36 adding } \\
\text { specific scales: } \\
\text { - } \quad \text { CLD-related symptoms } \\
\text { - } \quad \text { CLD-related effects on } \\
\text { - } \quad \text { activities of daily living, } \\
\text { - } \quad \text { Memcentration, } \\
\text { - } \quad \text { Sexual functioning } \\
-\quad \text { Sexual problems, } \\
-\quad \text { Sleep, } \\
-\quad \text { Loneliness, } \\
-\quad \text { Hopelessness, } \\
-\quad \text { Qual.of social interaction, } \\
-\quad \text { Health distress } \\
-\quad \text { Self-perceived stigma of CLD }\end{array}$ \\
\hline
\end{tabular}

IC: Internal consistency; TRT: Test Re-test reliability; CV: Construct validity; Conv. V: Convergent validity; DV: Discriminant validity; CLD: Chronic Liver Disease.

${ }^{*}$ All reported validities have been established

${ }^{* *}$ A prospectively validated Short Version of LDQOL has been published (Kanwal, 2008)

Table 3. The two most commonly used specific HRQOL instruments for candidates or recipients of liver transplantation (Jay, 2009) 


\subsubsection{Hepatitis quality of life questionnaire (HQLQ) (Bayliss, 1998)}

In addition to a standard SF-36 generic core, comprised of eight scales, HQLQ contains five generic items consisting of two questions for the social functioning scale and one question each for physical role, emotional role and vitality scales to augment existing SF-36 scales. HQLQ is addressed only to hepatitis $C$ patients. This instrument will be useful in studies of health outcome among patients with chronic hepatitis $\mathrm{C}$, a condition whose health burden appears to have been underestimated in studies to date.

\subsubsection{Chronic Liver Disease Questionnaire (CLDQ) (Younossi, 1999)}

This instrument introduced in 2000, has two parts: the generic SF-36 and six specific scales, with a number of individual items: abdominal symptoms, fatigue, systemic symptoms, activity, emotional function and worry. These items were selected based on 60 chronic liver disease patients, 20 liver experts and a review of the literature. Younossi et al. established construct validity according to significant differences in CLDQ scores according to Child's classification.

\subsubsection{Liver Disease Quality of Life Questionnaire (LDQOL) (Gralnek, 2000)}

LDQOL is a targeted instrument which incorporates the generic SF-36 as well as 12 diseasetargeted multi-item scales: liver disease-related symptoms, liver disease-related effects on activities of daily living, concentration, memory, sexual functioning, sexual problems, sleep, loneliness, hopelessness, quality of social interaction, health distress, and self-perceived stigma of liver disease. This questionnaire was designed for patients with liver disease, such as transplant candidates or liver transplant recipients. Gralnek et al., established the validity of this instrument for measuring QOL in patients with chronic liver disease in a multi-center study of patients referred for liver transplant evaluation. More recently a prospective validation of a short form version of the LDQOL including 36 targeted items representing nine domains in addition to the SF-36 has been published (Kanwal, 2008).

The LDQOL was published in 2000, but has only been introduced to clinics recently and some studies have been published (Dias Teixeira, 2005; Kim, 2007; Gotardo, 2008; Casanovas 2010;).

\subsubsection{National Institutes of Diabetes and Digestive and Kidney (NIDDK)}

The Liver Transplant Data Base (NIDDK-LTD), (Belle, 1997) which was developed from standardized instruments it is a QOL questionnaire for adults, which includes both physical and mental domains and specific areas. Unlike the previous specific instruments, it has not been developed in other cultures.

\subsection{Complementary QOL indexes}

Some complementary QOL indexes and questionnaires may allow implementation research. The opinion of several authors, such as Jay et al. however, is that, the lack of a gold-standard QOL instrument for liver transplant recipients is an impediment to cross-study comparisons. Depending on the objective of the study or the target population, complementary questionnaires should be used, since other areas may be affected in advanced liver disease (Foster, 1998; Dwigt, 2000; Gutteling, 2006). 


\subsubsection{Fatigue Impact Scale (FIS) (Fisk,1994; Hassoun, 2002; Jones, 2009)}

FIS is a validated questionnaire for assessing fatigue. It is used in many chronic conditions. The multidimensional assessment of fatigue is complicated by the interrelation of its multiple causes and effects. A significant proportion of liver patients suffer fatigue, even patients with non advanced disease. Fatigued patients have more sleep problems and higher depression scores than non-fatigued patients (Poynard, 2002). Self rated depression is present in $28 \%$ of fatigued patients compared with $4 \%$ of non-fatigued patients. Long term fatigue affects $68 \%$ of the patients with PBC but it is not related to the severity of their liver disease (Morana, 2009).

\subsubsection{Beck's Depression Inventory (BDI) (Beck, 1961)}

Beck's Depression Inventory is a 21-item self-report rating inventory measuring characteristic attitudes and symptoms of depression. The total score ranges between 0 and 63; scores below 14 are considered normal, scores from 14 to19 indicate mild to moderate depression, scores from 20 to 28 , moderate to severe depression, and scores higher than 28 are indicative of severe depression. This questionnaire is regularly used as a complementary measure.

\subsubsection{State-Trait Anxiety Inventory (STAI) (Guillén-Riquelme, 2011)}

Since physical symptoms associated with end-stage liver disease, such as poor appetite and fatigue, are also associated with depression, the scores of liver transplant candidates in three separate areas, somatic, cognitive, and affective, have to be computed. Therefore, the StateTrait Anxiety Inventory is one of the most frequently used instruments for measuring anxiety in adults and has been demonstarted to be valid and reliable. It consists of 20 statements that assess how respondents feel "generally." Scores can vary between 20 and 80, with higher scores indicating more anxiety.

\subsubsection{Cognitive Operations Preference Enquiry-Easy (COPE-EASY) (Francis, 2009)}

Independently of important cultural differences and health systems, coping with chronic diseases is crucial for patients and caregivers (Saab, 2011). The Coping Operations Preference Enquiry-Easy (COPE-Easy) consists of 32 questions, incorporating 15 distinct coping strategies that can be grouped into three subscales: active problem focused coping, avoidant coping and seeking social support (Gutteling 2007).

\section{Factors influencing QOL measurements: Age, gender, expectancies, cause of liver disease, differences between men and women and mode of administration}

Persons with severe liver disease often have a poor quality of life before liver transplantation (van den Plas, 2003). This poor quality of life is related to chronic disease and a decline in health caused by poor liver function (Marchesini, 2001). Medical treatments may be of some help in limiting symphtoms in cirrhosis and its complications (Hussain, 2001; Younossi, 2001; Girgrah, 2003; Gutteling, 2008). However, a more complete return of quality of life and health must usually wait until after recovery from a successful liver transplantation procedure (Castaldo, 2009). In addition, cross-cultural issues have to take into account (Hunt, 1986). 
Currently, liver transplantation is the treatment of choice in selected cases of acute and chronic liver failure and HRQOL reached is in general satisfactory, although below the level of the general population (Cleemput, 2007). Balanced results have been measured one year post- transplant (Takinella, 2010). Results, however, must be interpreted with caution as QOL improvements may have been overstated due to variables such as selection bias, exclusion of severely ill and deceased patients, too many short-term studies and suboptimal methodology (Younossi, 1998).

In the studies published about QOL after liver transplantation in the nineties, only generic instruments were used (Levy, 1995). It is only recently that QOL data have been obtained through specific liver disease questionnaires (Jay, 2009). We will mention some studies that have identified factors known to enhance QOL.

For example, patients with a history of alcoholism or who were regular drug users can be accepted in a transplant program only, after rehabilitation (Lucey, 2002; Gangeri, 2002). However, some studies observed that they have a greater incidence of psychiatric disease or psychological disorders which are responsible for a reduction in their QOL (Dew, 2000; 2001). Recent publications have addressed this problem, as a transplant candidates, alcoholic patients may be considered as a transplant candidates after psychiatric assessment. The detection of urinary ethylglucuronide allows the detection of alcohol consumption in alcoholic liver disease patients awaiting liver transplantation, (Erim, 2007), although fully consensued recommendations have not been achieved, the general recommendation is to dedicate more time assessing patients and increasing communication within the multidisciplinary transplant team (Kotlyar, 2008).

The differences in QOL between male and female patients continue to be a subject of research (Cowling, 2004; Lowry, 2010). QOL assessed gender differences have been detected in chronic illnesses: e.g. women scoring lower levels of QOL (Vazquez, 2004). The same results were obtained when assessing chronic HCV-related liver diseases. Teixeira et al. 2006, using the SF-36 or the specific LDQOL instrument found statistically significant differences. They tested differences in the following domains: liver disease symptoms, concentration, memory, worrying about the disease and sexual problems. Russell et al 2008, with the administration of, SF-36 the Center for Epidemiologic Studies Depression Scale (CES-D), and Beck Anxiety Inventory Scale, observed similar results.

Gifford. et al, in Australia, using the generic instrument SF-12, observed a reduction of QOL for women between 15 and 71 years of age (Gifford, 2003). While the reasons for the lower QOL in women have not yet been clearly defined, the findings indicate that social and cultural problems associated to the disease may be implicated. Interestingly, these observations have been repeated for different chronic conditions, backgrounds or geographic origins. In Spain this has been corroborated by Ferrer et al using the CLDQ (Ferrer, 2006 ).

The main concern among men is related to their professional activities; they are worried about not being able to provide for their families. Although there are different circumstances implicated in symptoms or in alteration in the QOL, the way that patients react to the diagnosis or treatments and its consequences are different in both genres (Gifford, 2005).

In our experience in the Liver Transplant Unit, we observed, using the generic NHP that three months after liver transplant women were scoring higher than men, but after six 
months men were improving progressively whereas women were not, not correlating with clinical results (data not published). These facts may corroborate the usual role of women in family life.

The weight of the stigma felt by liver disease sufferers in the past is still present nowadays (Scambler, 1998; 2009; Zickmund, 2004). Stigma is defined as the opinion of a dominant group with a preformed judgement about attitudes or situations considered socially unacceptable. Stigma is found in all levels of society (Zickmund, 2003).

One explanation is that drug use, a risk factor for AIDS and chronic HCV-related liver disease, projects a negative image of these diseases (Kanwal, 2005). In the past, before the discovery of the hepatitis $C$ virus in 1989, this situation was observed in cirrhosis patients who, despite not being drinkers, were always asked about their drinking habits and were sometimes labelled as alcoholics. Another reason is that people living with a carrier are afraid of being infected (Marcellin, 2007).

Women have reported experiencing greater stigma than men. The presence of this stigma can affect self-esteem and cause alteration in the QOL (Strauss, 2006).

The pre-transplant physician/patient relationship and the coordination with other members of the transplantation team are vital. At this stage, the medical information that patients receive and the attitudes of the medical team is highly significant (Cordoba, 2003; Zickmund, 2004; Flamme, 2008). Knowing about experiences of other patients with the same health problems is also positive. Information supplied to the patient and his/her family members as well as psychological and social support induces behavioural changes, which may be reflected in an improved physiological process (van der Plas, 2003).

Realizing that social and/or psychological factors play a significant role in patients' HRQOL, transplant teams could take advantage of information collected so far and implement new programs (Rodger, 1999; Pieber, 2006; van den Berg, 2006; DiMartini, 2011.)

\begin{tabular}{|l|l|l|}
\hline $\begin{array}{l}\text { Mode of } \\
\text { administration }\end{array}$ & Strengths & Weaknesses \\
\hline Self & Minimal resources required & $\begin{array}{l}\text { Greater likelihood of low } \\
\text { response rate }\end{array}$ \\
\hline Interviewer & $\begin{array}{l}\text { Maximizes response rate. } \\
\text { Few, if any, missing items } \\
\text { Requires many resources } \\
\text { training of interviewers } \\
\text { May diminish willingness to } \\
\text { acknowledge problems } \\
\text { Limits format of instrument }\end{array}$ \\
\hline Surrogate Responder & $\begin{array}{l}\text { Reduces stress for target group } \\
\text { (very sick or elderly) }\end{array}$ & $\begin{array}{l}\text { Perceptions of surrogate } \\
\text { may differ from target } \\
\text { group }\end{array}$ \\
\hline Telephone & $\begin{array}{l}\text { Few, if any, missing items } \\
\text { Minimizes errors of } \\
\text { misunderstanding } \\
\text { Less resource intensive than } \\
\text { Interviewer administered mode }\end{array}$ & $\begin{array}{l}\text { Requires resources training } \\
\text { of interviewers }\end{array}$ \\
\hline
\end{tabular}

Table 4. Modes of administration of questionnaires of HRQOL (Hays, 2009) 
Effects on the properties of questionnaires of HRQOL related to the mode of administration have been studied (Table 4) (Hays, 2009; Gundy, 2010). Significant differences were detected in measurements -after adjustment- researchers found that, for the Emotional Functioning (EF) scale, patients who had completed the written questionnaire at home had significantly lower levels of $(\mathrm{EF})$ compared to those interviewed over the telephone.

\begin{tabular}{|llll|}
\hline $\begin{array}{lll}\text { Child-Turcotte-Pugh }(\text { CTP), Prognosis of liver disease. } \\
(\text { CTP A }=5-6 \mathrm{p}, \mathrm{CTP} \mathrm{B}=7-9 \mathrm{p}, \mathrm{CTP} C=10-15 \mathrm{p})\end{array}$ & & & \\
& None & Controlled & Poor control \\
Ascites & None & Grade I-II & Grade III-IV \\
Encephalopathy & $<34$ & $34-50$ & $>50$ \\
Total bilirubin, $\mu \mathrm{mol} / \mathrm{L}($ normal $=17.1 \mu \mathrm{mol} / \mathrm{L})$ & $>3.5 \mathrm{~g} / \mathrm{dL})$ & $2.5-3.5 \mathrm{~g} / \mathrm{dL}$ & $<2.5 \mathrm{~g} / \mathrm{dL}$ \\
Albumin, $\mathrm{g} / \mathrm{L}$ & $<1.7$ & $1.7-2.2$ & $>2.2$ \\
INR & & & \\
\hline
\end{tabular}

Table 5. Scoring severity of liver disease MELD (Malinchoc, 2000; Kamath, 2001) and ChildPugh (Pugh, 1973). MELD score was developed to determine the severity of liver disease based on the patient's serum bilirubin, serum creatinine, and the international normalized ration (INR).It has been proposed to replace the Child-Turcotte-Pugh (CTP) score as a "more objective" measure of chronic liver disease severity

\section{HRQOL in patients with chronic liver disease is not associated with disease severity as measured by MELD (Model for End-stage Liver Disease) score}

Liver transplant is indicated in selected patients with advanced liver disease in which other therapeutic measures have failed or are not possible, and with no absolute contraindications for this procedure. (Consensus Document of the Spanish Society of Liver Transplant, 2009).

Some type of balance between need and utility has to be considered, meaning that we should be cautious with patients with a very severe clinical prognosis when taking advantage of a scarce resource, a liver graft. In our opinion, ideally, there should be a balance between the subjective perception of health by the patient, friends and close family and the clinical severity of the disease based on medical data when deciding on when to do the transplant.

However, some difficulties have to be taken into account. Clinicians base their decisions on objective measures, such as analysis and image tests for clinical diagnosis and treatment but the moment of transplant also depends on the waiting list and the feasibility of a suitable donor. Ideally, it would be desirable to consider both biological objective measures and more subjective measures, such as HRQOL (Kanwal, 2004).

HRQOL in chronic liver patients has been shown to be impaired in numerous studies. Gutteling et al. 2006, studied the impact of physical and psychosocial determinants on a weighted score of HRQOL in patients with chronic liver disease. They showed that HRQOL was related to disease severity and joint pain. Also depression, decreased appetite and fatigue were strongly related to HRQOL. In hepatitis $C$ patients, fatigue and depression were powerful determinants of HRQOL (Strauss, 2006). Patients with cirrhosis who had a 
higher Child-Pugh score (measuring disease severity) presented symptoms such as muscle cramps, pruritus, and fatigue (Marchesini, 2001), significant factors relating to QOL. Comorbid conditions and the duration of disease have not shown in the majority of studies a significant relationship with QOL in these patients. However, the relationship between psychological distress, symptoms and QOL is less known.

Some authors, studying the association between HRQOL and survival in patients with cirrhosis, showed that the relation between HRQOL and survival was MELD (Model of EnStage Liver Disease) independent (Kanwal, 2004; Saab, 2005). Kanwal et al., found that higher baseline HRQOL predicted lower mortality (Kanwal, 2009). Specifically, for each 1point increase in HRQOL, there was a $4 \%$ decrease in mortality. Both social relations and support have proved to be favourable predictors.

Considering that HRQOL has been recognized as an important outcome in chronic liver diseases, and clearly determined by disease severity, some changes might be applied in the clinical practice. For example, it could be useful to develop a form of intervention aimed at improving adaptation to the more frequently identified symptoms and to implement the use of a comprehensive assessment of QOL in the evolution of chronic liver disease patients with the aim of better clinical management.

However, in everyday practice, the instruments evaluating QOL in liver disease are rarely used due to lack of time and resource constraints (Sanders, 1998; Gutteling, 2007). Some doctors, having different priorities, are hesitant to implement this issue. MELD is being used to prioritize patients for liver transplantation, with the purpose of limiting mortality in patients on the waiting list (Wiesner, 2003). There are paucity of data evaluating associations between MELD score and patient-centered outcomes (HRQOL). Kanwal et al. in 2004 publication “Does Model for End-stage Liver Disease (MELD) predict HRQOL in patients with advanced chronic liver disease?" explore these associations. Their research on correlations between MELD/CTP and patient-centered outcomes evidenced that in persons with advanced chronic liver disease, MELD score predicts patient self-rated severity of liver disease symptoms, but fails to predict disability days and the more global outcome of HRQOL (Kanwal, 2004).

CTP score may be a better proxy measure than MELD, due to being based on clinical data and is more patient centered disease in persons with decompensated chronic liver disease (Saab, 2005). Both hepatic encephalopathy and ascites, which can affect quality of life, are not part of the MELD score. Furthermore, the MELD score has not been correlated with the severity of ascites and hepatic encephalopathy. Thus, liver disease severity assessed by the MELD score may no longer correlate with quality of life. (Saab, 2005) (Table 5).

MELD score allows prioritizing patients on the waiting list, putting the "sickest first" (Schaffer, 2003). However, we have to take into account that the MELD score does not always adequately reflect disease severity and prognosis (Frost, 2002). In patients with fulminant hepatic failure, metabolic disease, hepatocellular carcinoma, refractory ascites, hepato pulmonary syndrome etc. MELD does not apply (Schaffer, 2003).

Nowadays, although one of the most used disease severity indices is MELD score, it is not associated with HRQOL. Several patients with decompensated liver disease do not have a high enough MELD score, so we should examine possible causes of the present situation and justify and validate other specific instruments or formulas. 


\section{Does etiology of the liver disease appear to influence individual's HRQOL? Issues concerning Acute Liver Disease vs. Chronic Liver Disease}

Pretransplantation HRQOL scores are affected by the etiology of liver cirrhosis, therefore it is important the knowledge of the impact of a particular disease. Patients with hepatocellular and cholestatic etiologies have higher HRQOL scores than alcohol or viral hepatitis patients (Bianchi, 2003; Steel, 2007). Although the individual's perception of his/her state of health is crucial, different etiologies may identify some of the characteristics of the components of QOL in liver diseases (Krasnoff,2005). In general terms, younger and male people perceive a better QOL compared to older and women patients (Painter, 2001).

In early stages, liver disease patients show few or non-specific symptoms, therefore reporting insignificant effects on HRQOL. As the disease progresses to cirrhosis and complications arise (ascites, muscle cramps, fatigue etc.) individuals report noteworthy effects on HRQOL (Gutteling, 2006; Björnsson, 2009). In patients with advanced disease the etiology of the liver disease does not seem to influence patients' ratings. Although in earlier cases of chronic cholestatic liver disease significant pruritus and fatigue may have a significant impairment of HRQOL (Poupon, 2004). These symptoms that may also be observed in chronic hepatitis $\mathrm{C}$ may not be present in those with other forms of chronic liver disease such as chronic hepatitis B or iron overload (Lam, 2009).

We will explore the most important issues that have been developed in the last few years (Jay, 2009). Some determinants of HRQOL are derived from specific symptoms and concerns of liver diseases, but a generic HRQOL test is unable to measure them (Gutteling, 2007; Kotlyar, 2008). Examples of some specific problems observed in advanced liver disease are: sleep related problems, sleep pattern changes, stigma of liver disease, symptoms and effects of liver disease and their treatments (Holzner, 2001).

\subsection{Issues related to HRQOL in hepatitis $C$ and hepatitis $B$}

Patients with chronic hepatitis C assessed by the SF-36 show diverse and non specific symptoms (fatigue, anorexia, weight loss, abdominal distress...) and usually have significant reductions in their SF-36 scores for all of the scales (both mental and physical components) (Dwigt, 1998; Foster, 2000; Strauss, 2006) .

Patients with chronic hepatitis B virus (HBV) infection show a reduction in the SF-36 scores that assessed mental functions, but they have no reduction in the scores that measured physical symptoms, indicating that the symptoms associated with chronic HCV infection are qualitatively different to those associated with chronic HBV infection (Curry, 2004; Spiegel, 2005; Lam, 2009).

Patients with chronic HCV infection who had used intravenous drugs in the past had the greatest impairment in QOL scores, but the reduction in QOL scores was still found in patients who had never used drugs (Weissman, 1980; Fowler 1980). The reduction in QOL could not be attributed to the degree of liver inflammation or to the mode of acquisition of the infection. Recent studies have demonstrated through cerebral magnetic resonance images of abnormal cerebral metabolism and cognitive impairments in patients with chronic hepatitis C ( Hilsabeck, 2002; Forton, 2008; Bokemeyer, 2011) 


\subsection{Hepatocellular Carcinoma (HCC)}

Development of a malignant tumour might occur in a cirrhotic liver that can have a preserved liver function. For this reason, clinical guidelines recommend screening surveillance programs in every cirrhotic patient in order to detect possible tumours in early stages to assure treatment efficacy (Ruppert, 2010). Owing to recent advances in early stage liver tumour diagnosis, presumably, these patients do not have specific symptoms and their perceived HRQOL is perhaps stable, but due to the little research available in this area the result for the moment remains uncertain (Kotlyar, 2006; Steel, 2007).

Indications for orthotopic liver transplantation according to the European Liver Transplant Registry (2008), are the following. Virus related indication in 38\%; Alcoholic liver disease (ALD) related indication in 33\%, and $4 \%$ had combined aetiology of ALD and hepatitis C and B. (Varma, 2010)

We could assume that at the time of diagnosis of the HCC, patients may suffer distress and be disturbed by the prospect of a therapeutical intervention such as a possible liver transplant. If the HCC is diagnosed at an early stage the prognosis is good but the patient is not adapted to the disease as is the case in a chronic patient (Gangeri, 2007; Castaldo, 2009; Crone, 2010). After transplant they might have recurrent viral hepatitis which worsens the clinical situation and even the prognosis (Bownik, 2010). New approaches for the prophylaxis of recurrent hepatitis $C$ are under evaluation but whether this treatment will influence the severity of liver disease or the outcome of recurrence is still unknown.

\subsection{Alcoholic Liver Disease (ALD)}

Patient selection for liver transplantation has always been a demanding responsibility for transplantation teams and professionals. In alcoholic liver disease patients, issues related to liver transplantation have remained unresolved despite the convincing reports of similar survival post transplant in selected ALD patients, compared to those who received transplant for other indications (Roberts, 2004).

A period of abstinence is recommended for alcoholics before being considered possible candidates for transplant and before being accepted to undergo the procedure (Kotlyaar, 2008). Also a reasonable familiar and social support is required. DiMartini et al. have proposed a selection method to identify alcoholic patients suitable for transplantation. Lucey et al have reported on a multidisciplinary collaboration of transplant hepatologists, surgeons and psychiatrists that identifies psychosocial predictors of long term sobriety and compliance after liver transplant in alcoholics (Weinrieb and Lucey, 2007; Dew, 2008). Pretransplant abstinence has two purposes; it allows a window of opportunity for the liver to stabilize (it is not exceptional that some cases have been withdrawn from the waiting list due to improvement), and it allows the opportunity to examine the patient's commitment.

\subsubsection{Alcoholic Acute Hepatitis}

No systematic evaluation has been performed on patients transplanted for alcoholic liver disease (ALD). Data are limited on the impact of structured management of the alcohol problem on the risk of recidivism following transplantation in ALD. The question of a possible transplant during the acute episode remains unanswered. In these patients short 
term survival is good after transplant. However, due to the relative scarcity of donors, the majority of transplant teams do not accept to list patients who are actively consuming alcohol. (Cowling, 2004), but it is controversial (Mathurin, 2011).

\subsection{Autoimmune and Cholostatic Liver Diseases}

Liver transplant is a well established therapy for patients with autoimmune hepatitis (AIH), primary biliary cirrhosis (PBC) or primary sclerosing cholangitis (PSC). The perceived QOL in patients with cholestatic liver disease before and after LT was measured using some aspects of QOL, including symptoms (pruritus, fatigue); physical, social, and emotional functioning; health perceptions (stigma); and overall QOL (Gross, 1999). Changes in these QOL parameters before and after LT were studied and also the relationships between clinical and QOL factors and was demonstrated that cholestatic liver disease displayed the best cost-effectiveness ratio after LT (Longworth, 2003). Following transplantation QOL was substantially better than before transplantation and there were no differences in QOL parameters between patients with AIH, PBC and PSC. Some authors have pointed out that a patient's QOL 1 year after transplant could not be predicted by pre-transplantation QOL variables (Krasnoff, 2005; Bownik, 2009).

\subsection{Acute Liver Disease}

Acute liver failure continues to be associated with a high mortality rate, and emergency liver transplantation is often the only life-saving treatment (Riordan\& Williams, 2003). Although, the short-term outcomes are worse in comparison with those for non-urgent cases, due to the initial recovery process, the majority of patients transplanted with acute liver failure, reported that they have a good quality of life (Sargent, 2007; Dobbels, 2010). The keys to long-term success and continued progress in urgent liver transplantation are the use of good-quality whole grafts and a short waiting list time, both of which depend on access to a sufficient pool of organ donors. In this group the pre-transplantation HRQOL data could not be assessed due to patients' clinical situation. However, there have been studies published reporting an acceptable survival and QOL., in the short or medium term (Chan, 2009).

\subsection{Issues related to HRQOL in receptors HIV+}

More relevant problems at present are: - Primary disease recurrence, especially Hepatitis C virus, -Scarcity of donors, -Complications related to the chronic administration of immunodepressors (Tomé, 2008) The Spanish Liver Transplant Program for selected HIV+ carriers was initiated in 2002 due to the increasing burden of liver disease in patients with HIV (Joshi, 2011). Some new developments, both in the treatment of HIV+ and in the longterm management of liver transplant recipients have enabled further improvement of the results. (Consensus conference, 2009).

Studies are fragmented. Until recently different constructs and researches covered 1-2 years after transplantation and it is only now that there is a focus on the long term results. In acute liver failure a "better HRQOL related to shorter duration and lesser severity of liver disease" was observed. Disease recurrence has little impact on graft survival rates within 7-10 years of transplantation, in contrast, hepatitis $C$ recurrent disease is an important concern in relation to survival and QOL (Holzner, 2001; Karam, 2003; Sainz-Barriga, 2005). 
Survival of liver transplanted patients at five years depends on when the patients received liver transplant (K. Bjøro, 1999). In recent years, there has been considerable improvement in long-term clinical management and an increase in knowledge about risks, such as developing chronic renal disease, "de novo" tumours, primary disease recurrence etc. Present challenges are related to studies with a longer follow up, 10 to 20 years, some of which have been recently published (de Kroon, 2007; Ruppert, 2010).

\section{Indications of liver transplant and prioritization criteria on the waiting list}

When should a liver transplant be considered? There are medical and ethical concerns about the appropriate use of scarce resources, and the degree of priority given to patients with ALD has always been a controversial issue (Kotlyar, 2008). In recent years, approximately 1200 liver transplants have been performed in Spain yearly. This means that on average three livers are received every day.

Referrals to transplant centres should be made considering there is enough time to evaluate the candidate. Pretransplant evaluation and follow-up is a combined effort of clinicians, psychiatrists and substance abuse specialists. Assessment from medical, surgical and psychosocial points of view takes time and sometimes it can be like a race against time (Gutteling, 2007). Later referrals leave little scope to explore further medical management options or to allow time to work with the substance misuse or psychiatric team. Abstinence before transplantation evaluation and listing is important to select patients who would benefit the most from transplantation, as some would get better in this period (Drent, 2009). There should be reservations in listing patients with a lack of social support, active smokers, having psychotic or personality disorders, or a pattern of nonadherence.

\section{Studying QOL after liver transplant. Results in HCV, liver transplantation and QOL}

A review of quality of life instruments used in liver transplantation (Jay, 2009) has been recently published. Factors influencing the QOL of an individual patient include pretransplant disease severity, complications during the perioperative period, long-term adverse effects of immunosuppressive drugs, the etiology and recurrence of the underlying liver disease and the information received from the medical team throughout the process (Paterson, 2000).

Nowadays, liver transplantation is a common therapeutical option. However transplantation teams have to deal with strict selection of candidates, due to the relative shortage of donors. Moreover we have to take into consideration the present available information on the natural history regarding the risks of "de novo" diseases, or malignancy or the primary disease recurrence in the long term (Telles-Correia, 2011; Estraviz, 2007). Other goals may be more widely accepted, for example, describing functional health and HRQOL before and after transplantation; comparing contrast outcomes and exploring whether physiological performance, demographics, and other clinical variables are predictors of posttransplantation QOL (Bravata\& Keeffe, 2001; Ho, 2006; Aberg, 2009).

In particular, $\mathrm{HCV}$-infected patients generally report a worse QOL before transplant and a lesser increase in QOL after transplant than patients transplanted for other reasons (Feurer, 2002). 
The major predictors of poor adherence to medication gives an idea of how we can intervene early in treatment (Bernstein, 2002). There are few studies addressing QOL in relation with anti-HCV treatment after liver transplant (Alsatie, 2007; Neri, 2010). Patient and treatment factors to be aware of are treatment of asymptomatic disease; the presence of psychological problems, particularly depression; a patient's lack of belief in the benefit of treatment; the complexity of the treatment; and adverse events (Schiano, 2006). Other factors that perhaps are harder to quantify are a poor provider-patient relationship, inadequate follow-up or discharge planning, missed appointments, and the cost of medication, copayment, or both. (Ghobrial, 2001).

Liver transplant recipients do not, however, achieve the same QOL scores as healthy controls, and the prevalence of psychiatric comorbidities including depression is higher than controls (Dew, 1997). Patients experience more acute anxiety and depression, especially exalcoholics and hepatitis C patients (Paterson, 2000).

Despite few physical manifestations of disease at the time of HCV recurrence, patients report an impaired quality of life and functional status compared with other recipients without recurrence (Feurer, 2002). This suggests that patient knowledge of the diagnosis of recurrent HCV alone can negatively impact HRQOL (Hauser, 2004). They perceive themselves as unwell and have significant changes in their mental and physical health despite the absence of disease-related complications. However, only a limited number of studies have investigated the influence of gender, $\mathrm{HCV}$ genotype, or $\mathrm{HCV}$ antiviral treatment on the HRQOL of liver transplanted patients with HCV recurrence (Feurer, 2002; Saab, 2010).

Complexity of the treatment requires an extra effort by the transplant team, for example before patients leave the hospital after transplant. Adverse events of medication have to be taken into account, possibly in the long-term, due to poorer physical functioning, depression, and greater rates of fatigue some patients can miss some doses. More than $50 \%$ of liver transplants recipients survive more than 20 years, achieve important selfachievements, and report quality of life superior to patients with liver disease or other chronic conditions (Ruppert, 2010).

\section{Clinical relevance of measuring QOL and methodological difficulties}

Liver transplant is a surgery that restores both long-term physiology and well-being in patients with end-stage liver disease. (Tomé, 2008) Factors that have to be considered include the stress of waiting for a liver transplant - with its uncertainty in terms of both timing and outcome - as well as the physical and psychological demands of the procedure in the pre- and post-transplant period (Goetzmann, 2006). Other demands on the long term are linked to general quality of life (QOL) and treatment adherence (Drent, 2009).

It is necessary to differentiate the clinical situation of patients with acute liver disease versus those with chronic liver disease, due to the process of adaptation that usually happens in chronic diseases. Several cross-sectional and longitudinal studies show a statistically significant increase in QOL after transplantation in the majority of patients. Longitudinal studies are preferable to cross sectional studies.

Capture of the HRQOL experiences across disease severity and etiology of the liver disease is challenging because of subtle differences in the disease and the background of the person 
(Norman, 2003). Post-transplantation HRQOL scores are not affected in general by the etiology of the original liver cirrhosis, but transplant recipient scores continue to remain significantly lower than those of healthy patient controls. Prospective studies, showing the QOL evolution in the long term follow up, are starting to show differences between the cause of transplant and clinical evolution (Ruppert, 2010). Minimal clinical important difference is a concept defined as the minimal change in HRQOL which is important for the patient, allowing patients to report a minimal yet perceptible change in their health (Norman, 2003). Confirmation of the preliminary results in this group of patients is necessary.

Relapse of substance abuse, especially alcohol consumption, often affects not only QOL, but also adherence to immunosuppressive therapy and thus long-term survival after OLT. As relapse of alcohol addiction occurs in 10 to $30 \%$ of OLT recipients, continuous psychological support has an important role in post-transplant care (Pfitzmann, 2007).

The risk of recurrent disease in the graft influences the clinical prognosis. In previous alcoholics, or other addicts, disease recurs in a minority of patients. For example, in alcoholic disease histologically proven disease recurrence is not frequent whereas it is the rule in hepatitis $\mathrm{C}$, and is not common in cases of primary biliary cirrhosis, auto-immune hepatitis, or primary sclerosing cholangitis (Kotlyar, 2006).

In addition to being influenced by the psychological and physical condition of the patient, QOL is also affected by social function and occupational activity. Employment rates in liver transplanted recipients depend on several factors, such as age, education, duration of their disability and country. The number of patients returning to work after transplant ranges from $30 \%$ in Germany to about 55\% in the United States and Canada (Bravata, 2001; Aberg, 2009).

During the first 6 months after liver transplantation, the majority of physical and mental components of health-related quality of life scores improve, but these increases are not sustained in the long term (De Bona, 2000). At 1 year after liver transplantation, emotional and mental health-related quality of life scores are balanced with a tendency to decrease (Paterson, 2000). In the postoperative years 1 to 5, possible episodes of acute cellular rejection, recurrent disease and patient age over 60 years decrease physical function and overall general QOL scores (Levy, 1995). Beyond 5 years after liver transplantation, osteoporosis, and episodes of chronic rejection may decrease QOL scores through decreases in the physical function and bodily pain domains (Karam, 2003).

\section{The importance of psychological aspects}

With regard to psychopathology, it is important to note that it is not always a contraindication for transplant per se (Jowsey, 2001; Gutteling, 2010). Some studies however, show that psychiatric diagnosis is common among transplant candidates specially in patients with previous alcoholic liver disease and hepatitis $C$ carriers who may have worse clinical outcome after transplantation (Sherman, 2004).

Telles-Correia, et al, found that in the pre-transplant period, the prevalence of depression was observed in $33 \%$ of patients, anxiety was observed in 34\%, and dependency on alcohol or drugs was observed in 59\%. After transplant, depression prevalence was observed in $30 \%$, anxiety in $26 \%$, and psychosis in $6.4 \%$ (Telles-Correia, 2006). 
As we mentioned above, non-adherence before transplantation is predictive of nonadherence after transplantation. It is known that anti hepatitis $C$ virus viral treatment is associated with neuropsychiatric side effects (Quelhas,\& Lopes, 2009). Therefore, in these situations, psychopharmacological treatment is required to be initiated as soon as possible, especially in patients with a history of psychiatric disorder, to assure adherence to medication (Gangeri, 2007; Quelhas \& Lopes, 2009). Many factors may affect the process of adaptation to the disease (Kendall; 1995; Uchino, 1996; Telles-Correia, 2008). Patients can have different coping strategies, the most common being, stoic acceptance, denial, hopelessness, anxious concern and fighting spirit.

Coping strategies may change over time, depending on specific stressors and the development that follows the disease. Studies show that fighting spirit and denial are ways of coping better than the rest, in the sense that facilitate adjustment to illness (Carver, 2005; Russell, 2008).

\subsection{Psychosocial aspects in family and advanced liver disease}

Emotions are stressful for the patient and also for the family and can lead to physical and emotional exhaustion (Nickel, 2002). Family members usually have emotional troubles, sometimes overlapping those presented by the patient. The most common are: fear, anxiety, sleep disturbances, difficulty concentrating, loss of appetite, and fatigue (Sanders, 2008). When the patient gets all the attention, a feeling of isolation among other family members may appear (Pérez San Gregorio, 2008; Stilley, 2010). Moreover, other perceptions have been observed, such as guilt, when the patient is left alone, or fear of not doing enough or not doing something correctly, etc..,

It is also important to mention two phenomena that may affect the whole family, and they are: the conspiracy of silence and family claudication (Miyazaki, 2010). The conspiracy of silence attempts to prevent that the parties involved become aware of the diagnosis and prognosis of the disease. The results are the emergence of mistrust, isolation, limited emotional expression and isolation which can create family-physician-patient misleading relationships (Bolkhir, 2007). To avoid the conspiracy of silence we must always take into account the real needs and desires of the patient information that can change with the time (Carr, 2001).

Family claudication: expresses the absence of the family's ability to respond adequately to the demands and needs of the patient due to a state of exhaustion and an overwhelming feeling that results in difficulties in maintaining a positive communication between the patient, family members, and the healthcare team (Szeifert, 2010; Kramer, 2011).

\subsection{Psychosocial intervention in patients with advanced liver disease}

The role of the psychological assessment and monitoring during the pre-and post-transplant phases, has been recognized. Identifying and reducing psychological risk factors may play a role in the long-term success of transplantation (Crone, 2006).

Previous studies suggest that psychological intervention during the process of hepatitis $C$ disease and transplantation is important and necessary (Quelhas \&Lopes, 2009). Emotional support during the illness, before and after transplantation, both individually or in groups, can improve the emotional well being, HRQOL, survival, facilitate the adaptation and adherence of transplant candidates and transplant patients (Knott et al. 2006; Quelhas \& 
Lopes, 2009; Steel, 2007). The goals of psychological intervention are to improve the QOL in patients with liver disease, facilitating their adaptation to the disease, accepting adaptive coping strategies and ultimately improving the patient's sense of self-control (Goetzmann et al, found in a sample of 69 patients, that almost half $(47 \%)$ expressed the need for emotional support during the assessment for the procedure of liver transplantation (Goetzmann, 2007).

Van den Plas et al., showed that for transplant patients psychological support in the pre-and post-transplant periods besides the rehabilitation provided by the medical and nursing team and family, were one of the essential aspects of the transplant program (Van den Plas, 2003).

In mood disorders and anxiety disorder, psychopharmacological therapy in conjunction with psychotherapy may ameliorate the disturbance to the point at which patients can reach an emotional, and affective balance. Their equilibrium, allows them to manage the eventual distress related to the transplant (Crone, 2006). Such patients, however, need constant support before, during and after transplantation; during the pre-transplantation phase, specifically for sensitivity to stress, (Table 6) and in the post-transplant phase, most significantly because of immunosuppressant therapy that might precipitate mood swings, irritability, mania and anxiety. Psychotherapy and/or psychotherapy in conjunction with pharmacological treatment might be indicated during all the phases of the transplant process as they are individuals who tend to manifest traits such as depression, anxiety and phobia (Marcellin, 2007). Anxiety reduction techniques, autogenic training, systematic relaxation techniques, guided imagery, and pain management are recommended (Pasquini, 2006; Pelgur, 2009).

\begin{tabular}{||l|l|l||}
\hline \hline \multicolumn{1}{||l||}{ Informed consent } & \multicolumn{1}{|l||}{ Personality profile } & Psychopathology \\
\hline Past/present psychiatric history & \multicolumn{1}{|l||}{ Effect of illness on daily life activities } \\
\hline \multicolumn{2}{||l|}{ Use/abuse of alcohol and/or drugs } \\
\hline \multicolumn{2}{|l|}{ Defense mechanism employed and coping skills } & Treatment compliance \\
\hline \multicolumn{2}{|l|}{ Perceived Quality of Life } & Support from the family and friends \\
\hline Socioeconomic support (together with nurses team and social worker's evaluation) \\
\hline Awareness of information regarding the actual surgical event and future treatments \\
\hline
\end{tabular}

Table 6. Domains of the pre-transplant psychological evaluation

A mail survey was done to assess the importance of professionals assigned to psychosocial factors in evaluations for liver transplant candidacy and liver transplant surgeons from the highest volume liver transplant centers in the United States. Psychosocial evaluators assigned greater importance to availability of transportation, adaptation to stress and coping skills and were less likely than transplant surgeons to recommend that a patient with a history of poor social support be listed for liver transplant. The results of the study showed that factors identified by psychosocial evaluators are important and transplant outcomes should be studied (Santos Junior, 2007). 


\section{Experiences in our unit}

Our Liver Transplant Unit started the liver transplant program in 1984. In 1987 we began to study QOL using the generic test NHP (Figueras, 1989). Interestingly, this test allowed us to confirm that after one year of having received transplant, alcoholic patients showed a recovery in all questions related to their daily life. Their recuperation was similar to that of female patients transplanted for primary biliary cirrhosis. Our explanation was that exalcoholics, recipients of transplantation, not only resolved their medical problems while abstaining from alcohol but also experienced a global improvement and had better selfesteem. In our experience patients are offered a new outlook on life post-transplant. Even patients who are suffering from self-inflicted damage (ex-alcoholics or ex-drug users) perceive the donation as proof of solidarity, which sometimes results in them strengthening their relationships with family and friends and in some cases, renewing past relationships. Congress of Spanish Liver Transplantation Groups (1992 Murcia), lecture's main focus was to discuss the "QOL after liver transplant" and whether the etiology of alcohol could affect in the results. It is interesting that we have detected some ex-alcoholics who are riskier cases. They have to attend regular visits with the psychiatric team. After liver transplant some patients may relapse and return to alcohol use. Rehabilitation in these cases is also possible. In our experience, severe cases are the exception; younger males (under 50 years old) who have shown a strong tendency to relapse and who have presented severe cases of recidivism, with small likelihood of rehabilitation.

After 2000, due to the relevance of the use of a specific disease questionnaire for QOL assessment in clinical liver diseases and liver transplantation settings, we started using the LDQOL questionnaire, which was translated and adapted to the Spanish population by our group (Casanovas, 2003; 2007).

We then made correlations with clinical and analytical data pre and post-transplant, and with validation and outcome studies (Casanovas, 2010a). The administration of this long questionnaire is time consuming. We are therefore currently planning to administer the SFLDQOL questionnaire, which has already been validated by its authors ( Kanwal, 2008). Recently, some research on QOL in patients with chronic liver disease, with or without HCC, awaiting liver transplantation and the sensitivity to change of the LDQOL questionnaire to determination of the quality of life of liver transplanted patients prospectively followed for twoyears, has been presented.

The LDQOL 1.0 has proven to be a useful and valid tool for measuring QOL crosssectionally in patients with liver disease. However, its sensitivity to change, or capacity to reflect actual changes in QOL after an intervention of assumed effectiveness, has not been studied to date. Studies on sensibility to change assessed using a prospective follow up from baseline, before transplant to 2 years after transplant, were presented at the AASLD meeting (Casanovas, 2010 b).

\section{Recommendations for future QOL after liver transplant studies}

Areas of future research related to QOL might help to settle long term problems associated with liver transplantation. There are a number of reliable and valid instruments, however none of them can be considered as the gold standard outcome to be used in all situations. 
In future studies, more attention should be paid to the QOL outcomes in liver transplant recipients with alcoholic liver disease, hepatocellular carcinoma and those with hepatitis $C$. Some articles also suggest that female liver transplant recipients should receive special attention (Russell, 2008).

Others point out the importance of focusing on the recovering functions both during the initial period post-transplant and on the long term results. How the new available immunosuppressor drugs have to be adjusted will depend on further research incorporating HRQOL results. (Crone, 2006)

In relation to patients with previous addictions, there is no definitive biochemical test to identify alcohol relapse and the tests available have poor sensitivity and specificity, so emphasis on QOL is also important. More research is required in this field to detect alcohol ingestion before it has an effect on the new liver or when social and familiar behaviour could be difficult to manage. (Stilley, 2010)

More attention for caregivers, usually wives because men are more frequently affected by liver diseases, is required. In single patients, it is necessary to identify a circle of friends or other family members who are willing to support and take care of them. (Carver, 2005; Day, 2009; De Blesser, 2009).

Considering factors that could condition differences in the evolution, future researches should assess a larger number of cases than those done to date,and implement prospective studies.

\section{Conclusion}

In the last few years, it has been recognized that incorporating the patient's perspective on the outcomes of interventions is highly important. While the impact of a health condition on an individual is reflected by symptoms and altered functions, these reflect only part of the total impact of a disease, hence the need to capture the effects on perceptions of his/her self well-being. Moreover, the ratings of physicians on the presence or absence and severity of symptoms or functional limitations can differ from patients' ratings and even from person to person.

Among the measures representing the health effects from the perspective of the patient, are validated questionnaires of HRQL and QOL. Three content areas are crucial, symptoms, functions, and well-being. There are well developed psychometrically generic and disease specific indices suitable for particular areas of research or practice. Chronic liver disease patients perceived a lower measured HRQOL, compared to other chronic disease patients, especially those with advanced or decompensated liver disease.

The results of QOL studies help the physicians to have a better understanding of chronic liver disease patients, some of them candidates to transplantation others post-transplant, thus enabling them to provide their patients with better support. Recognizing the goal of restoration of maximal QOL is essential to create appropriate interventions and to have the required information in order to improve treatment adherence and provide more overall satisfaction with QOL after liver transplantation.

In clinical trials, evaluating new drugs or new treatment schedules, quality-of-life questionnaires should always be added to the usual criteria of toxicity, efficacy or other 
evaluations. Liver transplant outcomes have to be considered as both a life-saving intervention and also as an opportunity to improve QOL. Patient interests -reported QOLshould suggest opportunities for ongoing development and research in this area. Therefore, we conclude that psychological care should be offered in all health centers and included in the comprehensive care of patients with liver disease.

More research into the predictive and ethical aspects of psychosocial evaluation for liver transplant is needed. Further studies are necessary that include a complete evaluation of the effects of gender, age, socioeconomic status, education, and ethnicity in order to understand modifiable factors on HRQOL especially after HCV recurrence in transplanted patients that could greatly improve patient's QOL with specific interventions.

\section{References}

Aberg F, Rissanen AM, Sintonen H, et al. Health-related quality of life and employment status of liver transplant patients. Liver Transpl. 2009;15(1):64-72.

Alsatie M, Chalasani N, \& Kwo PY. Management of hepatitis C infection after liver transplantation. Drugs. 2007;67(6):871-885.

Armstrong G L., Alter M J., McQuillan G M. et al. The past incidence of hepatitis C virus infection: implications for the future burden of chronic liver disease in the United States. Hepatology 2000; 31: 777-782.

Bayliss M S., Gandek B., Bungay K M., et al. A questionnaire to assess the generic and disease-specific health outcomes of patients with chronic hepatitis C. Qual Life Res 1998; 7(1): 39-55.

Bayliss M S. Methods in outcomes research in hepatology: definitions and domains of quality of life. Hepatology 1999; 29 (6 Suppl.): 3S-6S.

Beck AT, Steer RA, Brown GK. Manual for the Beck Depression Inventory-II. San Antonio (TX): Psychological Corporation; 1996.

Beck AT, Ward CH, Mendelson M, et al. An inventory for measuring depression. Arch. Gen. Psychiatry 1961: 4: 561-571.

Belle SH, Porayko MK, Hoofnagle $\mathrm{JH}$, et al. Changes in quality of life after liver transplantation among adults. National Institute of Diabetes and Digestive and Kidney Diseases (NIDDK) Liver Transplantation Database (LTD). Liver Transpl Surg. 1997 Mar;3(2):93-104.

Bergner M., Bobbit R A., Kressel S., et al. The sickness impact profile: conceptual formulation and methodology for development of a health status measure. Int $J$ Health Serv 1976; 6(3): 393-415.

Bergner MBobbitt RA, Carter WB Gilson BS The Sickness Impact Profile: development and final revision of a health status measure. Med Care. 1981;19(8):787-805.

Bergner M. Quality of life, health status, and clinical research. Med Care 1989; 27(3 Suppl.): S148-156.

Bernstein D., Kleinman L., Barker C M., et al. Relationship of health-related quality of life to treatment adherence and sustained response in chronic hepatitis $C$ patients. Hepatology 2002; 35(3): 704-708.

Bianchi G, Loguercio C, Sgarbi D, et al. Reduced quality of life of patients with hepatocellular carcinoma. Dig Liver Dis 2003; 35(1):46-54. 
Björnsson E, Verbaan H, Oksanen A, et al. Health-related quality of life in patients with different stages of liver disease induced by hepatitis C. Scand J Gastroenterol 2009;44(7):878-887.

Bjøro K, Friman S, Höckerstedt K, et al. Liver transplantation in the Nordic countries, 19821998: changes of indications and improving results. Scand J Gastroenterol. 1999; 34(7):714-722.

Bokemeyer M, Ding XQ, Goldbecker A, et al. Evidence for neuroinflammation and neuroprotection in HCV infection-associated encephalopathy. Gut. 2011;60(3):370377.

Bolkhir A, Loiselle MM, Evon DM, et al Depression in primary caregivers of patients listed for liver or kidney transplantation. Prog Transplant. 2007;17(3):193-198

Borgaonkar MR, \& Irvine E J. Quality of life measurement in gastrointestinal and liver disorders. Gut. 2000;47; 3:444-454.

Bownik H \& Saab S. The effects of hepatitis C recurrence on health-related quality of life in liver transplant recipients. Liver Int. 2010;30:19-30.

Bownik H, Saab S. Health-related quality of life after liver transplantation for adult recipients. Liver Transpl. 2009;15 Suppl 2:S42-49.

Bravata D M., \& Keeffe E B. Quality of life and employment after liver transplantation. Liver Transplant 2001; 7: s119-123.

Brazier JE , Harper R , Jones NM ,et al. Validating the SF-36 health survey questionnaire: new outcome measure for primary care. BMJ 1992; 305(6846): 160-164.

Bruns H, Krätschmer K, Hinz U, et al. Quality of life after curative liver resection: a single center analysis. World J Gastroenterol. 2010;16(19):2388-2395.

Carr A J., Higginson I J. Are quality of life measures patient centred. BMJ 2001; 322(7298): 1357-1360.

Carver, C.S. Enhancing adaptation during treatment and the role of individual differences. Cancer Supplement (2005), 104 (11), 2602-2607.

Casanovas T, Vallejo G., Herdman M, et al. Validation of the Spanish version of the Liver Disease Quality of Life questionnaire in transplant patients. Transplant Proc. 2003;35 (5):1803-1805.

Casanovas T, Jané L, Herdman M, et al. Validation of the Spanish version of the liver disease quality of life instrument among candidates for liver transplant. Transplant Proc. 2007;39(7):2274-2277.

Casanovas T, Jané L, Herdman M, et al. Assessing outcomes in liver disease patients: reliability and validity of the Spanish version of the Liver Disease Quality of Life Questionnaire (LDQOL 1.0). Value Health. 2010a;13(4):455-462.

Casanovas T,Jane L, Herdman M et al Sensitivity to change of the LDQOL Questionnaire to determination of the quality of life of liver transplanted patients prospectively followed for two years. Hepatology, 2010b;52, suppl 1, 846A.

Castaldo ET, Feurer ID, Russell RT, et al. Correlation of health-related quality of life after liver transplant with the Model for End-Stage Liver Disease score. Arch Surg. 2009;144:167-172.

Chan G., Taqi A., Marotta P.,et al. Long-term outcomes of emergency liver transplantation for acute liver failure. Liver Transpl. 2009;15 (12):1696-1702. 
Cleemput I, \& Dobbels F. Measuring patient-reported outcomes in solid organ transplant recipients: an overview of instruments developed to date. Pharmacoeconomics. 2007;25(4):269-286.

Consensus document of the Spanish Society of Liver Transplantation. Waiting lists, liver transplantation and quality indicators. Gastroenterol Hepatol.2009; 32: 702-716

Coons SJ, Rao S, Keininger DL, \& Hays RD. A comparative review of generic quality-of-life instruments. Pharmacoeconomics 2000 Jan;17(1):13-35.

Cordoba J., Flavia M., Jacas C., et al. Quality of life and cognitive function in hepatitis C at different stages of liver disease. J Hepatol 2003; 39: 231-238.

Cordoba J., Reyes J., Esteban J I. et al. Labeling may be an important cause of reduced quality of life in chronic hepatitis C. Am J Gastroenterol 2003; 98(1): 226-227.

Cowling $\mathrm{T}$, Jennings LW, Goldstein RM, et al. Societal reintegration after liver transplantation: findings in alcohol-related and non-alcohol-related transplant recipients. Ann Surg. 2004;239:93-98.

Cowling T., Jennings L W., Goldstein R M., et al. Liver transplantation and health-related quality of life: scoring differences between men and women. Liver Transplant 2004; 10(1): 88-96.

Crone CC, Gabriel GM, \& DiMartini A. An overview of psychiatric issues in liver disease for the consultation-liaison psychiatrist. Psychosomatics. 2006;47(3):188-205. Review

Crone CC, Marcangelo MJ, \& Shuster JL Jr. An approach to the patient with organ failure: transplantation and end-of-life treatment decisions. Med Clin North Am. 2010;94(6):1241-1254.

Curry M P.. Hepatitis B and hepatitis C viruses in liver transplantation. Transplantation 2004; 78(7): 955-963.

Day, E., Best, D., Sweeting, R., Russell, R, et al. . Predictors of psychological morbidity in liver transplant assessment candidates: Is alcohol abuse or dependence a factor? Transpl Int 2009; 22 (6), 606-14.

De Bleser, L., Matteson, M., Dobbels, F., et al. Interventions to improve medicationadherence after transplantation: A systematic review. Transpl Int. 2009, 22 (8), 780797.

De Bona M, Ponton P, \& Ermani M . The impact of liver disease and medical complications on quality of life and psychological distress before and after liver transplantation. J Hepatol. 2000;33:609-615.

de Bruin AF, de Witte LP, Stevens F, et al..Sickness Impact Profile: the state of the art of a generic functional status measure. Soc Sci Med. 1992;35(8):1003-1014.

de Kroon L, Drent G, van den Berg AP,et al.; Liver Transplant Group Groningen. Current health status of patients who have survived for more than 15 years after liver transplantation. Neth J Med. 2007;65(7):252-258.

Desai R, Jamieson NV, Gimson AE, et al. Quality of life up to 30 years following liver transplantation. Liver Transpl. 2008;14:1473-1479.

Dew MA, Switzer GE, DiMartini AF, et al.Psychosocial assessments and outcomes in organ transplantation. Prog Transplant. 2000;10(4):239-259.

Dew MA, Kormos RL, DiMartini AF, et al. Prevalence and risk of depression and anxietyrelated disorders during the first three years after heart transplantation. Psychosomatics. 2001; 42(4): 300-313. 
Dew MA, DiMartini AF, Steel J, et al. Meta-analysis of risk for relapse to substance use after transplantation of the liver or other solid organs. Liver Transpl. 2008; 14(2) :159-172.

Dew MA, Switzer GE, Goycoolea JM, et al. Does transplantation produce quality of life benefits? A quantitative analysis of the literature. Transplantation. 1997; 64(9): 12611273.

Dias Teixeira M C, de Fatima Gomes de Sa Ribeiro M., \& Strauss E. A new insight into the differences among non-cirrhotic and cirrhotic patients using the liver disease quality of life instrument (LDQOL). Ann Hepatol 2005; 4: 264-271.

DiMartini A., Dew MA, Fitzgerald MG \& Fontes P. Clusters of Alcohol Use Disorders Diagnostic Criteria and Predictors of Alcohol Use After Liver Transplantation for Alcoholic Liver Disease. Psychosomatics 2008; 49:332-340.

DiMartini A., Dew M A., Chaiffetz D., et al. Early trajectories of depressive symptoms after liver transplantation for alcoholic liver disease predicts long-term survival. Am J Transplant. 2011;11:1287-1295.

Dobbels F, Berben L, De Geest S, et al A qualitative study exploring patients perceived quality of life following an emergency liver transplant for acute liver failure. Transplantation. 2010;90 (2):205-219.

Drent G, De Geest S, Dobbels F. et al. Symptom experience, nonadherence and quality of life in adult liver transplant recipients Neth J Med. 2009;67(5):161-168.

Duffy, JP.; Kao, K; Ko, C Y. et al. Long-Term Patient Outcome and Quality of Life After Liver Transplantation: Analysis of 20-Year Survivors. Annals of Surgery: 2010; 252 (4): 652-661.

Dwight M M., Kowdley K V., Russo J E., et al. Depression, fatigue, and functional disability in patients with chronic hepatitis C. J Psychosom Res 2000; 49(5):311-317.

Erim Y, Böttcher M, Dahmen U, et al. Urinary ethyl glucuronide testing detects alcohol consumption in alcoholic liver disease patients awaiting liver transplantation. Liver Transpl. 2007;13(5):757-761.

Estraviz B, Quintana JM, Valdivieso A, et al. Factors influencing change in health-related quality of life after liver transplantation. Clin Transplant. 2007;21(4):481-499.

European liver transplant registry www.eltr.org/

Ferrer M, Córdoba J, Garin O, et al. Validity of the Spanish version of the Chronic Liver Disease Questionnaire (CLDQ) as a standard outcome for quality of life assessment. Liver Transpl. 2006;12(1):95-104.

Feurer I D., Wright J K., Payne J L., et al. Effects of hepatitis C virus infection and its recurrence after liver transplantation on functional performance and health-related quality of life. J Gastrointest Surg 2002; 6(1):108-115.

Figueras J., Casanovas T., Rafecas A. et al. Quality of life after liver transplant. Med Clin (Barc). 1989;93(6):207-208.

Fisk J D, Ritvo P G Ross L, et al.,. Measuring the Functional Impact of Fatigue: Initial Validation of the Fatigue Impact Scale. Clin Infect Dis. 1994; 18 (Suppl 1): S79-S83.

Flamme NE, Terry CL, \& Helft PR. The influence of psychosocial evaluation on candidacy for liver transplantation. Prog Transplant. 2008;18:89-96.

Forton DM, Hamilton G, Allsop JM, et al. Cerebral immune activation in chronic hepatitis C infection: a magnetic resonance spectroscopy study. J Hepatol. 2008; 49(3):316-22. 
Foster GR, Goldin RD, \& Thomas HC. Chronic hepatitis C virus infection causes a significant reduction in quality of life in the absence of cirrhosis. Hepatology. 1998;27(1):209-212

Fowler R C, Liskow B I, \& Tanna V L. Alcoholism, depression, and life events. J Affect Disord 1980; 2: 127-135.

Francis JJ, Wileman SM, Bekker H, et al. Beliefs about surgery: Development and validation of an instrument to assess cognitive representations about surgery, in the context of a chronic illness. Psychol Health. 2009;24(10):1125-1137

Frost $\mathrm{MH}$, Bonomi AE, Ferrans CE, et al. Patient, clinician, and population perspectives on determining the clinical significance of quality-of-life scores. Mayo Clin Proc. 2002; 77(5):488-494.

Gangeri L, Tamburini M, Borreani C, et al. Candidates for liver transplantation for cancer: physical, psychological, and social conditions. Transplantation 2002;73(10):16271635.

Gangeri, L., Bosinio, M., Brunelli, C., et al. Phenomenology and emotional impact of neuropsychiatric symptoms in orthotopic liver transplant for hepatocellular carcinoma. Transplant Proc 2007;39(5):1564-1568.

Ghobrial RM, Steadman R, Gornbein J, et al. A 10-year experience of liver transplantation for hepatitis C: analysis of factors determining outcome in over 500 patients. Ann Surg. 2001;234(3):384-393; discussion 393-394.

Gifford S M, O'Brien M L, Bammer G, et al. Australian women's experiences of living with hepatitis C virus: results from a cross-sectional survey. J Gastroenterol Hepatol 2003; 18: 841-850.

Gifford S M, O'Brien M L, Smith A, et al. Australian men's experiences of living with hepatitis C virus: results from a cross-sectional survey. J Gastroenterol Hepatol 2005; 20: 79-86.

Gill TM, \& Feinstein AR. A critical appraisal of the quality of quality-of-life measurements. JAMA. 1994;272(8):619-626.

Girgrah N, Reid G, MacKenzie S, et al. Cirrhotic cardio-myopathy: does it contribute to chronic fatigue and decreased health-related quality of life in cirrhosis? Can J Gastroenterol. 2003;17(9):545-551.

Goetzmann L, Klaghofer R, Wagner-Huber R, et al. Psychosocial vulnerability predicts psychosocial outcome after an organ transplant: results of a prospective study with lung, liver, and bone-marrow patients. J Psychosom Res. 2007;62(1):93-100.

Gotardo DR, Strauss E, Teixeira MC, et al. Liver transplantation and quality of life: relevance of a specific liver disease questionnaire. Liver Int. 2008;28(1):99-106.

Gralnek IM, Hays RD, Kilbourne A, et al. Development and evaluation of the Liver Disease Quality of Life instrument in persons with advanced, chronic liver disease--the LDQOL 1.0. Am J Gastroenterol. 2000;95(12):3552-3565.

Gross CR, Malinchoc M, Kim WR, et al. Quality of life before and after liver transplantation for cholestatic liver disease Hepatology. 1999;29(2):356-364.

Guillén-Riquelme A, \& Buela-Casal G. Psychometric revision and differential item functioning in the State Trait Anxiety Inventory (STAI). Psicothema. 201123(3):510515. 
Gundy C M. \& Aaronson N K. Effects of mode of administration (MOA) on the measurement properties of the EORTC QLQ-C30: a randomized study. Health and Quality of Life Outcomes 2010, 8:35- 42.

Gutteling JJ, de Man RA, van der Plas SM, et al Determinants of quality of life in chronic liver patients. Aliment Pharmacol Ther. 2006; 23(11):1629-1635.

Gutteling J J., de Man R A., Busschbach J J., et al. Overview of research on health-related quality of life in patients with chronic liver disease. Neth J Med. 2007;65(7):227-234.

Gutteling J J., Darlington A S., Janssen H L., et al. Effectiveness of health-related quality-oflife measurement in clinical practice: a prospective, randomized controlled trial in patients with chronic liver disease and their physicians. Qual Life Res. 2008;17(2):195-205.

Gutteling J J., Duivenvoorden H J., Busschbach J J., et al. Psychological determinants of health-related quality of life in patients with chronic liver disease. Psychosomatics. 2010;51(2):157-165

Guyatt GH, Feeny DH \& Patrick DL. Measuring health-related quality of life. Ann Intern Med. 1993;15;118(8):622-629.

Hassoun Z., Willems B., Deslauriers J., et al. Assessment of fatigue in patients with chronic hepatitis C using the fatigue impact scale. Dig Dis Sci 2002; 47(12): 2674-2681.

Hauser W, Zimmer C, Schiedermaier P. et al. Biopsycosocial predictors of health-related quality of life in patients with chronic hepatitis C. Psychosom Med 2004; 66(6): 954-958.

Hays RD, \& Woolley JM. The concept of clinically meaningful difference in health-related quality-of-life research. How meaningful is it? Pharmacoeconomics. 2000;18(5):419423.

Hays R D., Kim S., Spritzer M A K. et al. Effects of mode and order of administration on generic health-related quality of life scores. Value Health. 2009;12(6):1035-1039.

Hilsabeck R C, Perry W, \& Hassanein T I. Neuropsychological impairment in patients with chronic hepatitis C. Hepatology 2002; 35(2): 440-446.

Holzner B, Kemmler G, Kopp M., et al. Preoperative expectations and postoperative quality of life in liver transplant survivors. Arch Phys Med Rehabil. 2001; 82(1):73-79.

Hunt SM. Cross-cultural issues in the use of socio-medical indicators. Health Policy. 1986;6(2):149-158

Hunt SM, \& McEwen J. The development of a subjective health indicator. Sociol Health Illn. 1980;2(3):231-246.

Hussain K B., Fontana R J., Moyer C A., et al. Co-morbid illness is an important determinant of health-related quality of life in patients with chronic hepatitis C. Am J Gastroenterol 2001; 96(9): 2737-2744.

Jay C L., Butt Z., Ladner D P., et al. A review of quality of life instruments used in liver transplantation. J Hepatol. 2009; 55(5):949-959.

J Ho J K, Ko H H, Schaeffer DF, et al. Sexual health after orthotopic liver transplantation. Liver Transplantation. 2006; 12 (10): 1478-1484.

Jones DE, Gray J.C. \& Newton J Perceived fatigue is comparable between different disease groups Q J Med 2009; 102(9):617-624.

Joshi D., O'Grady J., Dieterich D., et al. Increasing burden of liver disease in patients with HIV infection. Lancet. 2011;377(9772):1198-1209.

Jowsey, S.G.,Taylor, M.L., Scheekloth, T.D. et al. Psychosocial challenges in transplantation. J Psychiatr Pract 2001; 7 (6), 404-414. 
K Bjøro, S. Friman, K. Höckerstedt, P. et al. Liver Transplantations in the Nordic Countries, 1982-1998: Changes of Indications and Improving Results. Scandinavian Journal of Gastroenterology 1999, 34, (7): 714-722.

Kamath P S, Wiesner R H, Malinchoc M, et al. A model to predict survival in patients with end-stage liver disease. Hepatology 2001; 33(2): 464-470.

Kanwal F, Hays RD, Kilbourne AM, et al. Are physician-derived disease severity indices associated with health-related quality of life in patients with end-stage liver disease? Am J Gastroenterol 2004;99(9):1726-1732.

Kanwal F, Gralnek IM, Hays RD, et al. Impact of chronic viral hepatitis on health-related quality of life in HIV: results from a nationally representative sample. Am J Gastroenterol. 2005;100(9):1984-1994.

Kanwal F, Spiegel BM, Hays RD, et al.Prospective validation of the short form liver disease quality of life instrument. Aliment Pharmacol Ther. 2008;28 (9)1088-1101.

Kanwal F, Gralnek IM, Hays RD, et al.Health-related quality of life predicts mortality in patients with advanced chronic liver disease. Clin Gastroenterol Hepatol. 2009;7 (7): 793-799.

Karam VH, Gasquet I, Delvart V, et al. Quality of life in adult survivors beyond 10 years after liver, kidney, and heart transplantation. Transplantation. 2003;76 (12): 16991704

Kendall J C., Sherman M F. \& Bigelow G E. Psychiatric symptoms in poly-substance abusers: relationship to race, sex, and age. Addict Behav 1995; 20: 685-690.

Kim S, Choi KH, Hwang SG, et al. [Validation of the Korean version of liver disease quality of life (LDQOL 1.0) instrument]. Korean J Hepatol. 2007;13(1):44-50.

Knott A, Dieperink E, Willenbring ML, et al. Integrated psychiatric/medical care in a chronic hepatitis $\mathrm{C}$ clinic: effect on antiviral treatment evaluation and outcomes. Am J Gastroenterol. 2006;101(10):2254-2262

Kotlyar DS, Burke A, Campbell MS, et al. A critical review of candidacy for orthotopic liver transplantation in alcoholic liver disease. Am J Gastroenterol. 2008;103(3):734-743.

Kotlyar DS, Campbell MS, \& Reddy KR Recurrence of diseases following orthotopic liver transplantation. Am J Gastroenterol. 2006;101(6):1370-1378.

Kramer JR, Kanwal F, Richardson P, et al. Importance of patient, provider, and facility predictors of hepatitis $\mathrm{C}$ virus treatment in veterans: a national study. Am J Gastroenterol. 2011;106(3):483-491.

Krasnoff J B., Vintro A Q., Ascher N L., et al. Objective measures of health-related quality of life over 24 months post-liver transplantation. Clin Transplant 2005; 19(1): 1-9.

Lam ET, Lam CL, Lai CL, et al.Health-related quality of life of Southern Chinese with chronic hepatitis B infection. Health Qual Life Outcomes. 2009; 7(5):52-62.

Levy M F., Jennings L., Abouljoud M S., et al. Quality of life improvements at one, two, and five years after liver transplantation. Transplantation. 1995; 59(4):515-518.

Longworth L, Young T, Buxton M J, et al. Midterm cost-effectiveness of the liver transplantation program of England and Wales for three disease groups. Liver Transpl. 2003;9(12):1295-1307.

Lowry D, Coughlan B, McCarthy O, \& Crowe J. Investigating health-related quality of life, mood and neuropsychological test performance in a homogeneous cohort of Irish female hepatitis C patients. J Viral Hepat 2010;17(5):352-359. 
Lucey MR. Is liver transplantation an appropriate treatment for acute alcoholic hepatitis? J Hepatol 2002;36(6):829-831.

Malinchoc M, Kamath PS, Gordon FD, et al.A model to predict poor survival in patients undergoing transjugular intrahepatic portosystemic shunts. Hepatology. 2000; 31(4):864-871.

Mathurin P, Moreno C, Samuel D, et al. Early liver transplantation for severe alcoholic hepatitis. N Engl J Med 2011;365(19):1790-1800.

Marcellin F, Préau M, Ravaux I, et al. Self-reported fatigue and depressive symptoms as main indicators of the quality of life (QOL) of patients living with HIV and Hepatitis C: implications for clinical management and future research. HIV Clin Trials. 2007;8(5):320-327.

Marchesini G, Bianchi G, Amodio P, et al. Italian Study Group for quality of life in cirrhosis. Factors associated with poor health-related quality of life of patients with cirrhosis. Gastroenterology. 2001;120(1):170-178.

Miyazaki ET, Dos Santos R Jr, Miyazaki MC, et al. Patients on the waiting list for liver transplantation: caregiver burden and stress. Liver Transpl. 2010;16(10):1164-1168.

Morana JG. Psychological evaluation and follow-up in liver transplantation. World J Gastroenterol. 2009 14;15(6):694-696.

Neri, S., Bertino, G., Petralia, A., et al. A multidisciplinary therapeutic approach for reducing the risk of psychiatric side effects in patients with chronic hepatitis $C$ treated with pegylated interferon alpha and ribavirin. J Clin Gastroenterol 2010, 44 (9), 210-217.

Nickel R, Wunsch A, Egle UT,et al. The relevance of anxiety, depression, and coping in patients after liver transplantation. Liver Transpl 2002;8:63-71

Norman GR, Sloan JA, \& Wyrwich KW. Interpretation of changes in health-related quality of life: the remarkable universality of half a standard deviation. Med Care. 2003 May;41(5):582-592.

Osterberg L, \& BlaschkeT. Adherence to medication. Patient and Treatment factors. N Engl J Med 2005,4;353(5):487-497.

Painter P, Krasnoff J, Paul S M., et al. Physical activity and health-related quality of life in liver transplant recipients. Liver Transplant 2001; 7(5): 213-219.

Pasquini M, Biondi M, Costantini A, et al. Detection and treatment of depressive and anxiety disorders among cancer patients: feasibility and preliminary findings from a liaison service in an oncology division. Depress Anxiety. 2006;23(7):441-448

Paterson DL, Gayowski T, Wannstedt CF, et al. Quality of life in long-term survivors after liver transplantation: impact of recurrent viral hepatitis $C$ virus hepatitis. Clin Transplant. 2000;14(1):48-54.

Pfitzmann R, Schwenzer J, Rayes N, et al. Long-term survival and predictors of relapse after orthotopic liver transplantation for alcoholic liver disease. Liver Transpl. 2007; 13(2):197-205.

Szeifert L, Molnar MZ, Ambrus C, et al. Symptoms of depression in kidney transplant recipients: a cross-sectional study. Am J Kidney Dis. 2010;55(1):132-140.

Paterson D L, Gayowski T, Wanntedt C F, et al. Quality of life in long-term survivors after liver transplantation: impact of recurrent viral hepatitis $C$ virus hepatitis. Clin Transplant 2000; 14(1): 48-54.

Patrick D L, \& Deyo R A. Generic and disease-specific measures in assessing health status and quality of life. Med Care 1989; 27(3 Suppl.): S217-232. 
Pelgur, H., Atak, N. \& Kose, K.. Anxiety and depression levels of patients undergoing liver transplantation and their need for training. Transplant Proc. 2009;41(5):1743-1748.

Pérez San Gregorio MA, Martín Rodríguez A \& Pérez Bernal J. Psychological differences of patients and relatives according to post-transplantation anxiety. Span J Psychol. 2008;11 (1): 250-258.

Pieber K, Crevenna R, Nuhr MJ et al. Aerobic capacity, muscle strength and health-related quality of life before and after orthotopic liver transplantation: preliminary data of an Austrian transplantation centre J Rehabil Med 2006;38(5):322-328.

Poupon R E., Chretien Y., Chazouilleres O., et al. Quality of life in patients with primary biliary cirrhosis. Hepatology 2004;40(2):489-494.

Poynard T., Cacoub P., Ratziu V., et al. Fatigue in patients with chronic hepatitis C. J Viral Hepatol 2002;9(4):295-303.

Pugh R N., Murray-Lyon I M., Dawson J L., et al. Transection of the esophagus for bleeding oesophageal varices. Br J Surg 1973;60(8):646-649.

Quelhas R, \& Lopes A. Psychiatric problems in patients infected with hepatitis C before and during antiviral treatment with interferon-alpha: a review. J Psychiatr Pract 2009; 15(4):262-281.

Rannard A., Buck D., Jones D E., et al. Assessing quality of life in primary biliary cirrhosis. Clin Gastroenterol Hepatol 2004; 2: 164-174.

Riordan S \& Williams R. Cause and prognosis in acute liver failure. Liver Transpl 2003; 5: 86-89

Roberts MS, Angus DC, Bryce CL, et al. Survival after liver transplantation in the United States: A disease-specific analysis of the UNOS database Liver Transpl. 2004; 10(7):886-897.

Rodger A J., Jolley D., Thompson S C., et al. The impact of diagnosis of hepatitis C virus on quality of life. Hepatology 1999;30(5):1299-1301.

Roila F, \& Cortesi E Quality of life as a primary end point in oncology. Annals of Oncology 2001;12, suppl 3:S3-6.

Ruppert K, Kuo S, DiMartini A,\& Balan V. In a 12-year study, sustainability of quality of life benefits after liver transplantation varies with pretransplantation diagnosis. Gastroenterology. 2010;139(5):1619-1629.

Russell RT, Feurer ID, Wisawatapnimit P, et al. The effects of physical quality of life, time, and gender on change in symptoms of anxiety and depression after liver transplantation. J Gastrointest Surg. 2008;12(1):138-144.

Saab S, Ibrahim AB, Shapner A, et al. MELD fails to measure quality of life in liver transplant candidates. Liver Transpl 2005;11(2):218-223.

Sainz-Barriga M., Baccarani U., Scudeller L., et al. Quality-of-life assessment before and after liver transplantation. Transplant Proc 2005;37(6):2601-2604.

Sanders C, Egger M, Donovan J, et al. Reporting on quality of life in randomised controlled trials: bibliographic study. BMJ. 1998;317(7167):1191-1194.

Sanders C, Rogers A, Gately C, et al. Planning for end of life care within lay-led chronic illness self-management training: the significance of 'death awareness' and biographical context in participant accounts. Soc Sci Med 2008;66(4):982-993.

Santos Junior, R., Miyazaki, M.C., Domingos, N.A., et al. Patients undergoing liver transplantation: psychosocial characteristics, depressive symptoms, and quality of life. Transplant Proc 2008;40(3):802-804. 
Sargent S \& Wainwright SP. A qualitative study exploring patients perceived quality of life following an emergency liver transplant for acute liver failure. Intensive Crit Care Nurs 2007;23(5): 272-280.

Scambler G. Stigma and disease: changing paradigms. Lancet 1998; 352(9133): 1054-1055.

Scambler G. Health-related stigma. Sociol Health Illn. 2009;31(3):441-455.

Schaffer RL, Kulkarni S, Harper A, et al.The sickest first? Disparities with model for endstage liver disease-based organ allocation: one region's experience. Liver Transpl. 2003;9(11):1211-1215.

Schiano T D, Martin P. Management of HCV infection and liver transplantation. Int J Med Sci 2006; 3: 79-83.

Sherman KE, Sherman SN, Chenier T \& Tsevat J. Health values of patients with chronic hepatitis C infection. Arch Intern Med. 2004;164 (21):2377-2382.

Spiegel B M., Younossi Z M., Hays R D., et al. Impact of hepatitis C on health related quality of life: a systematic review and quantitative assessment. Hepatology 2005;41(4):790800.

Steel JL, Chopra K, Olek MC, \& Carr BI. Health-related quality of life: Hepatocellular carcinoma, chronic liver disease, and the general population. Qual Life Res 2007a;16(2):203-215.

Steel, J.L., Nadeau, K., Olek, M., et al.. Preliminary results of an individually tailored psychosocial intervention for patients with advanced hepatobiliary carcinoma. J Psychosoc Oncol. 2007b;25(3):19-42.

Stewart A L., Greenfield S., Hays R D., et al. Functional well-being of patients with chronic conditions. Results from the medical outcomes study. JAMA 1989; 262: 907-913.

Stilley CS, DiMartini AF, Tarter RE,et al. Liver transplant recipients: individual, social, and environmental resources. Prog Transplant 2010;20(1):68-74.

Strauss E, \& Dias Teixeira MC Quality of life in hepatitis C. Liver Int 2006;26(7):755-765.

Szeifert L, Molnar MZ, Ambrus C, et al. Symptoms of depression in kidney transplant recipients: a cross-sectional study. Am J Kidney Dis. 2010;55(1):132-140.

Takinella R., Kawut S M., Brown R S. Jr, et al. Health-related quality of life and survival in liver transplant candidates. Liver Transpl 2010;16(2):238-245.

Telles-Correia D, Barbosa A, Barroso E, \& Monteiro E Psychiatric approach of liver transplant. Acta Med Port. 2006;19(2):165-179.

Telles-Correia, D., Barbosa, A., Barroso, E., et al. Psychiatric approach of liver transplant. Acta Med Port., 2006;19(2):165-179

Teixeira R, Pastacaldi S, Papatheodoridis GV., et al. Recurrent hepatitis C after liver transplantation. Journal of Medical Virology 2000; 61(4): 443-454.

Teixeira MC, Ribeiro Mde F, Gayotto LC. Worse quality of life in volunteer blood donors with hepatitis C. Transfusion. 2006;46(2):278-283.

Telles-Correia D., Barbosa A., Mega I., et al Psychiatric differences between liver transplant candidates with familial amyloid polyneuropathy and those with alcoholic liver disease. Prog Transplant 2008;18(2):134-139.

Telles-Correia D., Barbosa A., Mega I., et al. Mental health and quality of life in alcoholic liver disease patients after liver transplantation: a prospective controlled study. Transplant Proc. 2011;43(1):184-186.

Tome S, Wells JT, Said A., et al. Quality of life after liver transplantation. A systematic review. J Hepatol. 2008; 48(4):567-577. 
Uchino B N., Cacioppo J T., \& Kiecolt-Glaser J K.. The relationship between social support and physiological processes: a review with emphasis on underlying mechanisms and implications for health. Psychol Bull 1996;119(3):488-531.

Unal G., de Boer J B., Borsboom G J., et al. A psychometric comparison of health-related quality of life measures in chronic liver disease. J Clin Epidemiol 2001;54(6):587-596.

van den Berg-Emons R, Geert Kazemier G, van Ginneken B, et al. Fatigue, level of everyday physical activity and quality of life after liver transplantation J Rehabil Med 2006; 38: 124-129.

van den Plas S M., Hansen B E., de Boer J B., et al. Generic and disease-specific health related quality of life in non-cirrhotic, cirrhotic and transplanted liver patients: a cross-sectional study. BMC Gastroenterol 2003; 3: 33-46.

Varma V, Webb K., \& Mirza D F. Liver transplantation for alcoholic liver disease Liver transplantation for alcoholic liver disease. World J Gastroenterol. 2010;16(35):43774393

Vazquez I., Valderrabano F., Fort I., et al. Differences in health-related quality of life between male and female hemodialysis patients. Nefrologia 2004; 24(2): 167-178.

Ware J E. Jr, \& Sherbourne C D. The MOS 36-item short-form health survey (SF-36) I. Conceptual framework and item selection. Med Care 1992; 30(6): 473-483.

Ware J E .Jr, Bayliss M S., Mannocchia M., et al. Health-related quality of life in chronic hepatitis C: impact of disease and treatment response. The interventional therapy group. Hepatology 1999; 30(2): 550-555.

Weinrieb RM \& Lucey MR Treatment of addictive behaviors in liver transplant patients Liver Transplantation 2007; 13, Suppl 2, S79-82.

Wiesner R, Edwards E, Freeman R, et al. United Network for Organ Sharing Liver Disease Severity Score Committee Model for end-stage liver disease (MELD) and allocation of donor livers. Gastroenterology. 2003;124(1):91-96.

Weissman M M., Myers J K., \& Harding P S. Prevalence and psychiatric heterogeneity of alcoholism in a United States urbancommunity. J Stud Alcohol 1980; 41(7): 672-681.

Younossi Z M. \& Guyatt G. Quality-of-life assessments and chronic liver disease. Am J Gastroenterol 1998; 93(7): 1037-1041.

Younossi Z M., Guyatt G., \& Kiwi M. Development of a disease specific questionnaire to measure health-related quality of life in patients with chronic liver disease. Gut 1999; 45(2): 295-300.

Younossi Z M., Boparai N., Price L L., et al. Health-related quality of life in chronic liver disease: the impact of type and severity of disease. Am J Gastroenterol 2001; 96(7): 2199-2205.

Zickmund S., Ho E Y., Masuda M., et al. "They treated me like a leper". Stigmatization and the quality of life of patients with hepatitis C. J Gen InternMed 2003; 18(10): 835-844.

Zickmund S., Hillis S L., Barnett M J., et al. Hepatitis C virus-infected patients report communication problems with physicians. Hepatology 2004; 39(4): 999-1007. 


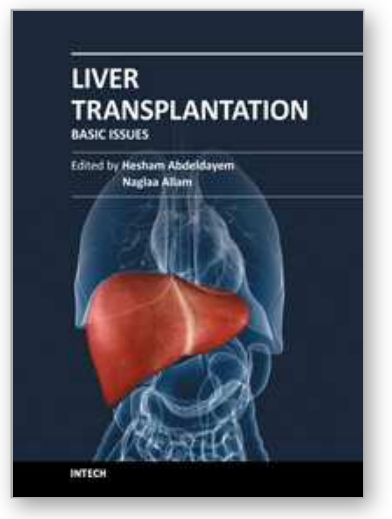

\author{
Liver Transplantation - Basic Issues \\ Edited by Prof. Hesham Abdeldayem
}

ISBN 978-953-51-0016-4

Hard cover, 418 pages

Publisher InTech

Published online 15, February, 2012

Published in print edition February, 2012

This book covers a wide spectrum of topics including history of liver transplantation, ischemia-reperfusion injury, immunology of liver transplantation, viral hepatitis and liver transplantation, other indications for liver transplantation, prognostic factors and perioperative period. The authors of the chapters are experts in their respective fields. They are proponents covering different aspects of liver transplantation and come from many centers across the world. The interdisciplinary approach and the authority of the contributors resulted in a valuable reference to anyone interested in developing a global view in liver transplantation including medical students, residents, fellows, nurses, and practicing physicians and surgeons as well as researchers in the field of liver transplantation.

\title{
How to reference
}

In order to correctly reference this scholarly work, feel free to copy and paste the following:

Teresa Casanovas Taltavull, Maria Carmen Peña-Cala and Eva Rodríguez Bruzos (2012). Disease Targeted Measures of Health Related Quality of Life (HRQOL) in Patients with Advanced Liver Disease Before and After Liver Transplantation, Liver Transplantation - Basic Issues, Prof. Hesham Abdeldayem (Ed.), ISBN: 978-95351-0016-4, InTech, Available from: http://www.intechopen.com/books/liver-transplantation-basicissues/disease-targeted-measures-of-health-related-quality-of-life-hrqol-in-patients-with-advanced-liver-di

\section{INTECH}

open science | open minds

\author{
InTech Europe \\ University Campus STeP Ri \\ Slavka Krautzeka 83/A \\ 51000 Rijeka, Croatia \\ Phone: +385 (51) 770447 \\ Fax: +385 (51) 686166 \\ www.intechopen.com
}

\author{
InTech China \\ Unit 405, Office Block, Hotel Equatorial Shanghai \\ No.65, Yan An Road (West), Shanghai, 200040, China \\ 中国上海市延安西路65号上海国际贵都大饭店办公楼 405 单元 \\ Phone: +86-21-62489820 \\ Fax: +86-21-62489821
}


(C) 2012 The Author(s). Licensee IntechOpen. This is an open access article distributed under the terms of the Creative Commons Attribution 3.0 License, which permits unrestricted use, distribution, and reproduction in any medium, provided the original work is properly cited. 